\title{
Comparison between a Public and Private Hospital in Terms of Patient Safety Culture
}

\author{
Birkan Tapan ${ }^{\mathrm{a}}$ \\ Albena Gayef ${ }^{b}$ \\ Ayşegül Yıldırım Kaptanoğlư
}

\begin{abstract}
Patient safety culture is a comprehensive set of practices that focus on the prevention of medical errors and transparency in event reporting. Moreover, to ensure patient safety in healthcare institutions, creating an effective patient safety culture is extremely important. Therefore, the purpose of this study is threefold. First, it identifies the perceptions of patient safety culture among healthcare professionals at two different hospitals (one public and one private) in Istanbul, Turkey $(n=80)$. Second, using two different surveys (the Hospital Survey on Patient Safety Culture and the Socio-demographic Survey), it examines whether such perceptions differ according to the roles and socio-cultural variables of the healthcare professionals. Third, it determines the main factors that influence effective patient safety culture. In the evaluation of the data, the frequency, percentage, arithmetic mean, independent samples t-test, the one-way analysis of variance (ANOVA), and the Tukey HSD test were employed. The data were evaluated using SPSS 21.0 statistical software, and the significance was accepted as $p<.05$. The findings show that the scores for the sub-dimension management support for patient safety was significantly higher for females than males $(p=.017$ ), whereas the scores for the sub-dimension feedback and communication about errors among the healthcare professionals with a postgraduate's degree were significantly higher than those with an associate's degree $(p=.011)$. Based on the results, it is recommended that a patient safety culture be created by all healthcare institutions to implement an effective system for reporting errors, to provide training, and to ensure ongoing improvements in patient safety culture.
\end{abstract}

Keywords: Patient $\bullet$ Hospital $\bullet$ Quality $\bullet$ Health management $\bullet$ Patient safety culture

a Corresponding author

Assist. Prof. Birkan Tapan, Ph.D., Department of Management of Healthcare Organization, Vocational School of Health Services, Istanbul Bilim University, Istanbul Turkey

Email: birkan.tapan@istanbulbilim.edu.tr

b Assist. Prof. Albena Gayef, Ph.D., Department of Medical Education and Informatics, Faculty of Medicine, Istanbul Bilim University, Istanbul Turkey

Email: albena.gayef@istanbulbilim.edu.tr

c Prof. Ayşegül Yıldırım Kaptanoğlu, M.D., Ph.D., Department of Health Management, Faculty of Health Sciences, Trakya University, Edirne Turkey

Email: draysegulyildirim@gmail.com 
Patient safety culture plays an important role in terms of developing patient safety practices in healthcare organizations. In general, healthcare services differ from other sectors in three ways: 1) they are utilized at the same time that they are produced; 2) they are composed of high-risk processes; and 3) they are directly related to human life. For these reasons, such services must be well-designed, and any probable risks must be eliminated (Aydin, 2009, p. 58).

Risk management in healthcare services mainly involves the concept of patient safety. According to the National Patient Safety Foundation, patient safety means the avoidance/mitigation of undesired results associated with healthcare services or prevention/reduction of errors that occur during healthcare services (http://www.npsf.org/). Although patient safety has recently occupied a wider space in the agenda of health professionals, the matter is not a new one. After a review of recent academic studies on patient safety, the following results were obtained. In 1964, Schimmel found that $20 \%$ of 240 patients at a university hospital were injured under care, and among this percentage of patients, $20 \%$ suffered serious and lethal injuries (Schimmel, 1964, p. 100). Another study, based on the records of approximately 20,000 patients hospitalized in California, found that $4.5 \%$ of patients suffered untoward events, and 1\% had suffered due to neglect (Mills, 1978, p. 360). In 1981, Steel found that $36 \%$ of the patients at a training hospital were injured, with $25 \%$ of them sustaining life-threatening injuries. Among the latter cases, 50\% involved the misadministration of medication (Berwick, 2006). In 1989, Gopher defined that the mean rate of error per patient was 1.7 (Small \& Barach, 2002). In the Harvard Practice Study, $4 \%$ of patients at hospitals in New York suffered injuries under care. However, $69 \%$ of the cases were preventable in nature (Harvard Medical Study Group, 1990). In a report published by the Institute of Medicine (IOM) in 2000, deaths due to medical errors in the U.S. were the fifth highest among the general causes of death. According to the IOM report, 44,000-98,000 individuals lose their lives every year due to medical errors, and the resulting costs of such errors range from US $\$ 17$ billion to as high as US $\$ 29$ billion (Center for Disease Control and Prevention [CDC], 2001).

Although First Do No Harm is the first and primary principle of healthcare service provision, the high number of medical errors continues to be presented in each subsequent study. In addition, it has been revealed that such errors can lead 
to many significant outcomes for patients and healthcare organizations, some of which are presented under the following statements (Sur \& Palteki, 2013):

- It may result in the death of the patient

- It may cause permanent and severe damage to the patient

- It may require additional treatment

- It may extend the patient's period of hospitalization

- It may elevate hospital costs

At this point, the parts of patient safety that are under threat by healthcare professionals have emerged, and preventive policies and road maps have been created against them. However, the practice is still not at the desired level, even if the U.S. has pioneered the majority of these efforts (Sur \& Palteki, 2013). Therefore, the creation of patient safety culture in hospitals should remain a priority in the healthcare field.

With regard to the term "patient safety culture," safety is defined as the condition under which the legal order runs without disturbance in the public order and where individuals can live without fear (Türk Dil Kurumu, 2005, p. 817). Meanwhile, culture includes numerous definitions in the literature. According to Kroeber, Kluckhohn, Untereiner, and Meyer (1952), culture is one's way of thinking, feeling, and behaving that reveals unique structures of human groups, which are expressed in created and transmitted symbols. The basis of culture is constituted by traditional opinions (created and selected in the historical process), which are particularly attributable to them. In addition, cultural systems are the products of behavior and are, in contrast, the conditions of future behavior (Kroeber et al., 1952). Common definitions of safety culture in the literature are given under the following statements:

- Safety culture stands on the contributions of every individual within an organization

- It is a concept that expresses the values shared by all members of an organization and all organizational groups

- It is related to official safety problems in an organization 
- It evaluates the association between reward systems and safety performance

- It affects the behaviors of members in an organization, especially in the working environment

- It reflects the desires of members in an organization to view any accidents and errors as learning opportunities

- It is quite durable, stationary, and resistant to change (Zhang, Wiegmann, von Thaden, Sharma, \& Gibbons, 2004)

Patient safety consists of the measures taken by healthcare organizations and healthcare professionals to prevent harm to their patients. More specifically, the main objectives of patient safety are to establish a system that will prevent the occurrence of any errors during the provision of services and protects patients from any harm arising from such errors (Tanrikulu, 2010).

Patient safety culture has an important role in the provision of safe healthcare services, and it is important that patient safety be adopted by all employees in the healthcare field (Fleming \& Wentzell, 2008, p. 15). Providing healthcare services without causing any harm to the patient is an utmost priority (Zhang et al., 2004). Studies conducted in Turkey have revealed that patient safety culture has not been properly perceived, and there is no structured patient safety system in effect (Tanrikulu, 2010).

The establishment of patient safety culture begins with an evaluation of the current culture in a healthcare organization (Fleming \& Wentzell, 2008, p. 15). Such an assessment focuses on the perception and behavior of employees and managers in a healthcare organization in order to diagnose the areas that need to be improved and/or redeveloped (Nieva \& Sorra, 2003, pp. 17-23). Healthcare organizations may assess safety culture and use the results for the following purposes (Yardımc1, Başbakkal, Beytut, Muslu, \& Ersun, 2014):

- To define areas that need improvement

- To diagnose patient safety culture for increasing patient safety awareness

- To assess patient safety interventions or programs and observe the changes that occur over time 
- To perform internal and external benchmarking

- To fulfill requests or requirements for regulation

Therefore, the purpose of this study is threefold. First, it identifies the perceptions of patient safety culture among healthcare professionals at two different hospitals (one public and one private) in Istanbul, Turkey. Second, it examines whether such perceptions differ according to the roles and sociocultural variables of the healthcare professionals. Third, it determines the main factors that influence an effective patient safety culture.

\section{Method}

This study was conducted on healthcare professionals employed by one public hospital and one private hospital in Istanbul, Turkey $(n=80)$ in 2014. To determine if perceptions differ according to the roles and socio-cultural variables of healthcare professionals, two different surveys were used: the Hospital Survey on Patient Safety Culture (Agency for Healthcare Research and Quality, Improving patient safety in hospitals: A resource list for users of the AHRQ Hospital Survey on patient safety culture, 2014) and the Socio-demographic Survey. The Hospital Survey on Patient Safety Culture was developed in 2004 in the U.S. by the Agency for Healthcare Research and Quality to assess patient safety culture in hospitals. The validity and reliability of the survey in Turkey was verified by the research of Bodur and Filiz (2010). This survey comprises 42 items and 12 sub-dimensions: overall perceptions of patient safety, frequency of events reported, teamwork across hospital units, handoffs and transitions, supervisor/manager expectations and actions promoting safety, organizational learning and continuous improvement, teamwork within units, communication openness, feedback and communication about errors, non-punitive response to errors, staffing, and management support for patient safety. In the evaluation of the data, the frequency, percentage, arithmetic mean, independent samples $t$-test, the one-way analysis of variance (ANOVA), and the Tukey HSD test were employed. The data were evaluated using SPSS 21.0 statistical software, and the significance was accepted as $p<.05$. 


\section{Results}

Table 1

Frequency Distribution of the Health Professionals' Sociodemographic Variables

\begin{tabular}{llcc}
\hline Variables & & $N$ & $\%$ \\
\hline \multirow{2}{*}{ Gender } & Woman & 42 & 52.5 \\
& Man & 38 & 47.5 \\
\hline \multirow{3}{*}{ Working years at the hospital } & 21 years and older & 1 & 1.3 \\
& $16-20$ years & 4 & 5.0 \\
& $11-15$ years & 13 & 16.3 \\
& $6-10$ years & 30 & 37.5 \\
& $1-5$ years & 16 & 32.5 \\
Working hours in a week (on average) & $<1$ year & 6 & 7.5 \\
\hline \multirow{3}{*}{ Profession } & $20-39$ hours & 10 & 12.5 \\
& $40-59$ hours & 69 & 86.3 \\
& 60-79 hours & 1 & 1.3 \\
\hline \multirow{2}{*}{ Type of hospital } & Nurse & 41 & 51.3 \\
& Physician & 16 & 20.0 \\
Total & Technician & 23 & 28.7 \\
\hline & $18-25$ & 16 & 20.0 \\
& $26-33$ & 24 & 30.0 \\
& $34-41$ & 17 & 21.3 \\
& $42-49$ & 22 & 27.5 \\
& 50 and older & 1 & 1.3 \\
\hline \multirow{3}{*}{ Educational status } & High School & 16 & 20.0 \\
& Associate's degree & 34 & 42.5 \\
& Bachelor's degree & 18 & 22.5 \\
& Postgraduate degree & 12 & 15.0 \\
\hline & Public & 44 & 55.0 \\
& Private & 36 & 45,0 \\
\hline & & 80 & 100.0 \\
\hline
\end{tabular}

It was found that $52.5 \%$ of the health professionals in this study were female, $37.5 \%$ had worked 6-10 years at their respective hospitals, $86.3 \%$ worked an average of $40-59$ hours a week, $51.3 \%$ were nurses, $20 \%$ were physicians, $28.7 \%$ were technicians, $30 \%$ were in the $26-33$ age group, $42.5 \%$ had an associate's degree, $55 \%$ worked at the public hospital, and $45 \%$ were employed by the private hospital (Table 1). 


\begin{tabular}{lccc}
\hline Table 2 & \multicolumn{4}{c}{ Gender } \\
The Healthcare Professionals' Patient Safety Culture Sub-dimension Mean Scores according to Gender \\
\hline Variables & \multicolumn{4}{c}{ Female } & Male & \\
\hline \multirow{2}{*}{ Patient Safety Culture Sub-dimensions } & $\mathrm{X} \pm \mathrm{SS}$ & $\mathrm{X} \pm \mathrm{SS}$ & $p$ \\
\hline Overall perceptions of patient safety & $2.54 \pm 0.59$ & $2.40 \pm 0.60$ & .324 \\
Frequency of events reported & $3.59 \pm 1.04$ & $3.79 \pm 1.00$ & .381 \\
Teamwork across hospital units & $2.65 \pm 0.78$ & $2.52 \pm 0.61$ & .435 \\
Handoffs and transitions & $2.81 \pm 0.89$ & $2.58 \pm 0.72$ & .213 \\
Supervisor/manager expectations and actions promoting safety & $3.18 \pm 1.05$ & $3.16 \pm 0.95$ & .930 \\
Organizational learning and continuous improvement & $2.43 \pm 0.84$ & $2.34 \pm 0.55$ & .553 \\
Teamwork within units & $2.62 \pm 0.85$ & $2.37 \pm 0.57$ & .126 \\
Communication openness & $2.15 \pm 0.95$ & $2.18 \pm 0.90$ & .888 \\
Feedback and communication about errors & $2.55 \pm 0.85$ & $2.46 \pm 0.63$ & .595 \\
Non-punitive response to errors & $2.76 \pm 0.53$ & $2.65 \pm 0.32$ & .230 \\
Staffing & $2.68 \pm 0.87$ & $2.61 \pm 0.67$ & .699 \\
Management support for patient safety & $2.80 \pm 0.82$ & $2.41 \pm 0.62$ & $.017^{*}$ \\
\hline
\end{tabular}

* Statistical significance

When we compared the healthcare professionals' mean scores of the Hospital Survey on Patient Safety Culture according to gender, there was a significant difference in the scores of the sub-dimension management support for patient safety $(p<.05)$ (Table 2$)$. In addition, the scores of the sub-dimension management support for patient safety were significantly higher for the females than the males (Table 2).

\begin{tabular}{lccc}
\hline Table 3 & & & \\
The Healthcare Professionals' Patient Safety Culture Sub-dimension & Mean & Scores based on the Type of Hospital \\
\hline Variables & \multicolumn{4}{c}{ Type of Hospital } \\
\hline \multirow{2}{*}{ Patient Safety Culture Sub-dimensions } & Public & Private & \\
& $\mathrm{X} \pm \mathrm{SS}$ & $\mathrm{X} \pm \mathrm{SS}$ & $p$ \\
\hline Overall perceptions of patient safety & $2.59 \pm 0.43$ & $2.33 \pm 0.74$ & .065 \\
Frequency of events reported & $3.75 \pm 1.11$ & $3.62 \pm 0.91$ & .570 \\
Teamwork across hospital units & $2.67 \pm 0.57$ & $2.49 \pm 0.83$ & .251 \\
Handoffs and transitions & $2.76 \pm 0.81$ & $2.63 \pm 0.82$ & .497 \\
Supervisor/manager expectations and actions promoting safety & $2.04 \pm 0.73$ & $2.31 \pm 1.10$ & .209 \\
Organizational learning and continuous improvement & $2.39 \pm 0.63$ & $2.38 \pm 0.82$ & .975 \\
Teamwork within units & $2.47 \pm 0.63$ & $2.54 \pm 0.85$ & .681 \\
Communication openness & $2.85 \pm 0.95$ & $3.57 \pm 0.93$ & $.001^{*}$ \\
Feedback and communication about errors & $2.50 \pm 0.66$ & $2.51 \pm 0.86$ & .949 \\
Non-punitive response to errors & $2.71 \pm 0.31$ & $2.71 \pm 0.57$ & .977 \\
Staffing & $2.70 \pm 0.76$ & $2.58 \pm 0.81$ & .494 \\
Management support for patient safety & $2.62 \pm 0.70$ & $2.61 \pm 0.83$ & .918 \\
\hline
\end{tabular}

* Statistical significance 
When comparing the healthcare professionals' mean scores on the Hospital Survey on Patient Safety Culture according to the type of hospital, there was a significant difference in the scores of the sub-dimension communication openness $(p<.05)$ (Table 3). Moreover, the scores for this sub-dimension by those employed at the private hospital were significantly higher than those working at the public hospital (Table 3). No significant difference was found in the mean scores of the other sub-dimensions according to the type of hospital $(p>.05)$ (Table 3).

\begin{tabular}{|c|c|c|c|c|}
\hline \multicolumn{5}{|c|}{$\begin{array}{l}\text { Table } 4 \\
\text { The Healthcare Professionals' Patient Safety Culture Sub-dimensions Mean Scores according to Profession }\end{array}$} \\
\hline Variables & & Profession & & \\
\hline Patient Safety Culture Sub-dimensions & $\begin{array}{l}\text { Physician } \\
\mathrm{X} \pm \mathrm{SS}\end{array}$ & $\begin{array}{c}\text { Nurse } \\
\mathrm{X} \pm \mathrm{SS}\end{array}$ & $\begin{array}{l}\text { Technician } \\
\mathrm{X} \pm \mathrm{SS}\end{array}$ & $p$ \\
\hline Overall perceptions of patient safety & $2.56 \pm 0.76$ & $2.46 \pm 0.55$ & $2.44 \pm 0.58$ & .820 \\
\hline Frequency of events reported & $4.06 \pm 0.95$ & $3.43 \pm 0.99$ & $3.89 \pm 1.05$ & .057 \\
\hline Teamwork across hospital units & $2.81 \pm 1.01$ & $2.62 \pm 0.65$ & $2.37 \pm 0.47$ & .152 \\
\hline Handoffs and transitions & $2.83 \pm 1.16$ & $2.72 \pm 0.69$ & $2.59 \pm 0.77$ & 0.666 \\
\hline Supervisor/manager expectations and actions promoting safety & $3.52 \pm 1.09$ & $3.17 \pm 1.00$ & $2.94 \pm 0.90$ & 0.220 \\
\hline Organizational learning and continuous improvement & $2.35 \pm 1.00$ & $2.37 \pm 0.71$ & $2.44 \pm 0.48$ & 0.900 \\
\hline Teamwork within units & $2.47 \pm 0.97$ & $2.58 \pm 0.71$ & $2.39 \pm 0.60$ & 0.600 \\
\hline Communication openness & $2.15 \pm 1.16$ & $2.09 \pm 0.74$ & $2.30 \pm 1.06$ & 0.697 \\
\hline Feedback and communication about errors & $3.08 \pm 1.09$ & $2.36 \pm 0.65$ & $2.37 \pm 0.40$ & $0.002^{*}$ \\
\hline Non-punitive response to errors & $2.92 \pm 0.69$ & $2.68 \pm 0.37$ & $2.62 \pm 0.28$ & 0.100 \\
\hline Staffing & $2.64 \pm 1.04$ & $2.63 \pm 0.73$ & $2.68 \pm 0.68$ & 0.974 \\
\hline Management support for patient safety & $2.68 \pm 0.99$ & $2.76 \pm 0.77$ & $2.31 \pm 0.42$ & 0.072 \\
\hline
\end{tabular}

* Statistical significance

When comparing the healthcare professionals' mean scores on the Hospital Survey on Patient Safety Culture according to their professions, the scores for the sub-dimension feedback and communication about errors showed a significant difference $(p<.05)$ (Table 4). In addition, the scores for this sub-dimension by the physicians were found to be significantly higher than those of the nurses (Table 4). No significant difference was found in the mean scores of the other sub-dimensions according to profession $(p>.05)$ (Table 4). 


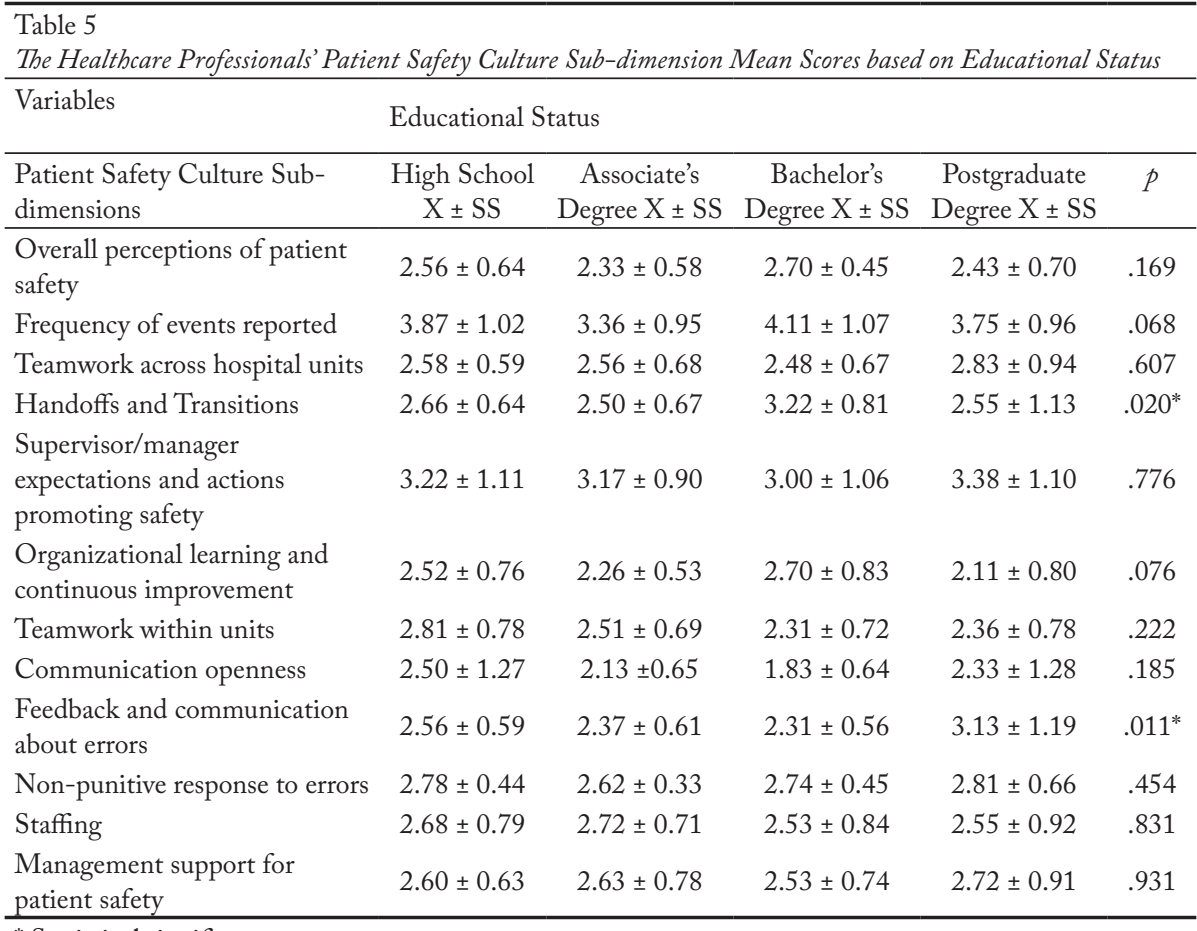

* Statistical significance

When comparing the healthcare professionals' mean scores on the Hospital Survey on Patient Safety Culture according to their educational status, there was a significant difference in the mean scores of the sub-dimension handoffs and transitions and feedback and communication about errors $(p<.05)$ (Table 5). Table 5 shows that the handoffs and transitions scores of those who completed highschool were significantly higher than those with an associate degree, whereas the scores of those with a bachelor's degree were significantly higher than those with an associate's degree. Furthermore, the mean scores for the sub-dimension feedback and communication about errors by those with a postgraduate's degree were significantly higher than those with an associate's degree, whereas the scores for the same sub-dimension by those with a postgraduate's degree were significantly higher than those with a bachelor's degree (Table 5). No significant difference was found in the mean scores of the other sub-dimensions according to educational status $(p>.05)$ (Table 5). Moreover, there was no significant difference in the sub-dimension scores according to age, the working years at the hospital, and the average weekly working hours $(p>.05)$. 


\section{Discussion and Conclusion}

In the Hospital Survey on Patient Safety Culture, a significant difference was found in the sub-dimension communication openness according to the type of hospital in which the healthcare professionals were employed $(p<.05)$ (Table 3). For example, the scores of those employed at the private hospital were significantly higher than those working at the public hospital (Table 3 ). Simultaneously, a study conducted by Gündoğdu and Bahçecik (2012) revealed that there was a significant difference in the mean scores of the communication openness sub-dimension $(p<.05)$. In the present study, no significant difference was observed among the other sub-dimensions in the Hospital Survey on Patient Safety Culture. In contrast, in the study conducted by Gündoğdu and Bahçecik (2012), there was a significant difference in the mean scores of the following sub-dimensions according to the type of hospital: overall perceptions of patient safety, frequency of events reported, teamwork across hospital units, handoffs and transitions, supervisor/manager expectations and actions promoting safety, organizational learning and continuous improvement, teamwork within units, communication openness, feedback and communication about errors, non-punitive response to errors, staffing, and management support for patient safety.

In the present study, there was no significant difference in the sub-dimension scores of the Hospital Survey on Patient Safety Culture according to age. In compliance with the results of this study, other studies have revealed that patient safety culture does not change by age (Bognar et al., 2008; Yang, Wang, Chang, Guo, \& Huang, 2009).

In a study conducted by Teleş (2011), there was no significant difference among the following patient safety culture sub-dimensions according to age $(p>.05)$ : teamwork in units, manager expectations and patient safety development activities, comprehensive perception of safety, communication and feedback on errors, keeping. communication channels open, error reporting frequency, employee supply, and nonpunitive response to errors. However, there was a significant difference in the mean scores of organizational learning and continuous improvement, management support for patient safety, and teamwork across hospital units according to age $(p<$ $.05)$. A significant difference was also found in the sub-dimension organizational learning and continuous improvement among the 30 years or younger age group, the 31-40 age group, and the 41 years or older age group $(p<.05)$. The $31-40$ 
age group were shown to have a higher perception of organizational learning and continuous improvement compared with the 30 years or younger age group $(p=.034)$. The members of the 41 years or older age group had a higher level of perception of organizational learning and continuous improvement compared with the 30 years or younger age group $(p=.007)$. A significant difference was found among the 30 years or younger age group and the 31-40 age group in terms of management support for patient safety $(p<.05)$. The members of the $31-$ 40 age group were observed to have a higher perception of management support compared with the 30 years or younger age group $(p=.034)$. In addition, a significant difference was found among the 30 years or younger age group, the 31-40 age group, and the 41 years or older age group in terms of teamwork across hospital units $(p<.05)$. Furthermore, the members of the 31-40 age group were seen to have a higher perception of teamwork across hospital units compared with the 30 years or younger age group $(p=.040)$. Finally, the members of the 41 years or older age group had a higher perception of teamwork across hospital units compared with the 30 years or younger age group $(p=.018)$ (Teleş, 2011).

In the present study, there was no significant difference in the sub-dimension scores of the Hospital Survey on Patient Safety Culture according to the working years at the hospital and the average weekly working hours $(p>0.05)$. In another study supporting this finding, no statistically significant difference was found in any of the 12 patient safety culture levels according to time of service at the hospital, time of employment in the profession, and weekly working hours $(p>$ .05) (Gözlü, 2011). Moreover, in other research studies, the patient safety culture level revealed no significant difference among healthcare professionals in terms of the time of employment in the healthcare organization (Dağdelen, 2014).

There was a significant difference in the mean scores of the sub-dimension management support for patient safety according to gender in our study $(p<.05)$ (Table 2). However, the scores for management support for patient safety were found to be significantly higher for females compared with males (Table 2). In addition, we found that there was no significant difference according to gender in the other sub-dimensions of the Hospital Survey on Patient Safety Culture. Simultaneously, other studies have revealed no significant difference among the sub-dimensions of patient safety culture according to gender (Çelen, Teke, \& Cihangiroğlu, 2014; Teleş, 2011). 
In the present study, significant differences were found in the mean scores of the sub-dimension feedback and communication about errors according to profession $(p<.05)$ (Table 4). For example, the scores of the physicians were significantly higher compared with the nurses $(p=.005)$. No significant difference was found in the mean scores of overall perceptions of patient safety according to profession ( $p>$.05) (Table 4). In contrast, Akın, Üçel, and Doğan (2010) reported that overall perceptions of patient safety was higher for nurses compared with physicians, whereas Koraşl1, Torun, and Yüzden (2010) reported a completely contrary result that the perception of physicians was higher than that of nurses.

There was a significant difference in the mean scores of the sub-dimension handoffs and transitions and feedback and communication about errors in our study $(p<.05)$ (Table 5). Table 5 shows that the bandoffs and transitions scores by those who completed high school were significantly higher than those with an associate's degree, whereas the scores of those with a bachelor's degree were significantly higher than those with an associate's degree. In addition, the mean scores of the sub-dimension feedback and communication about errors by those with a postgraduate degree were significantly higher than those with an associate's degree, whereas the scores of those with a postgraduate degree were significantly higher than those with a bachelor's degree $(p<.05)$. No significant difference was found in the other sub-dimensions. Apart from these results, in a study conducted by Gündoğdu and Bahçecik (2012) on the patient safety culture perception of nurses, the mean score of the nurses with an associate's degree in the sub-dimension management support for patient safety were significantly higher than nurses with a bachelor's degree $(p<.01)$ or those who were graduates of healthcare vocational schools. Finally, the mean scores of the sub-dimension frequency of events reported by the nurses who were graduates of healthcare vocational schools were significantly higher than those with an associate's degree $(p<.05)$, whereas the mean scores for supervisor/manager expectations and actions promoting safety by nurses with a postgraduate degree were significantly higher than those who were graduates of healthcare vocational schools $(p<.01)$.

In another study conducted by Teleş (2011) on healthcare professionals' patient safety culture perception, there was no statistically significant difference among groups according to professional status, especially in terms of the following sub-dimensions: teamwork within units, organizational learning and continuous 
improvement, overall perceptions of patient safety, feedback and communication about errors, communication openness, frequency of events reported, staffing, and nonpunitive response to errors $(p>.05)$. However, a statistically significant difference was observed between manager expectations and patient safety development activities, management support for patient safety, and teamwork among hospital units according to profession $(p<.05)$. Moreover, a significant difference was found among nurses, physicians, and other healthcare professionals for manager expectations and patient safety development activities. For example, the physicians had a higher perception of manager expectations and patient safety development activities compared with the nurses $(p=.004)$, whereas the other healthcare professionals had a higher perception of this sub-dimension compared with the nurses $(p=.000)$. A significant difference was also found among other healthcare professionals compared with the groups of physicians and nurses in terms of management support for patient safety $(p=.000)$. However, the other healthcare professionals also displayed a higher level of perception compared with that of the physicians in terms of management support for patient safety ( $p$ $=.000)$. The perception of the other healthcare professionals was also higher at the level of management support for patient safety compared with the nurses ( $p=$ .000). In addition, there was a significant difference among the other healthcare professionals, the physicians, and the nurses in terms of teamwork among hospital units. Finally, the perception of the other health professionals with regard to teamwork among hospital units was higher compared with the physicians $(p=$ $.000)$, whereas the perception of the other health professionals for this subdimension was higher compared with the nurses $(p=.000)$ (Teleş, 2011).

In conclusion, managers must dedicate themselves to this particular subject to create a permanent and effective patient safety culture. Moreover, managers must declare that all concerned parties are dedicated to patient safety and that he/she should encourage open communication between health professionals and patients, delegate responsibilities to define and reduce the procedures that threaten patient safety, and ensure continuous training for all health professionals with regard to patient safety. Patient safety must also be considered as a vital part of a corporate culture, and managers should highlight any high-risk activities as well as create an environment in which medical errors can be reported without fear and hesitation. Furthermore, this environment must not unreasonably condemn those who commit errors. Through these 
approaches, hospitals and healthcare organizations can ensure the creation of viable solutions for high-risk applications, consider patient safety programs as a vital part of quality improvement, and ensure that the organization itself can provide the resources to support an effective patient safety culture.

\section{References}

Agency for Healthcare Research and Quality. (2014). Improving patient safety in hospitals: A resource list for users of the AHRQ Hospital Survey on patient safety culture. Retrieved February 11, 2014 from http://www.ahrq.gov/professionals/quality-patientsafety/patientsafetyculture/hospital/resourcelist/hospimpptsaf.pdf

Akın,A.,Üçel, A. Ş., \& Doğan, N. (2010). Göztepe Eğitim Araştırma Hastanesi’nde hasta güvenliği kültürünün algılanması ve çalı̧̧an uzman hekim, asistan hekim ve hemşirelerin hasta güvenliği kültürüne yönelik tutumlarının belirlenmesi. In II. Uluslararası Sağllkta Performans ve Kalite Kongresi Bildiriler Kitabı (Vol.1., pp. 98-104). Antalya.

Aydın, B. (2009). Sağlıkta kalite. Sağlık Hizmetlerinde Kalite, Akreditasyon ve Hasta Güvenliği Dergisi, 1(1), 58-61.

Berwick D. M. (2006). IHI 100K lives campaign. Retrieved June 1, 2006 from http:// www.ihi.org/IHI/Programs/Campaign/

Bodur, S., \& Filiz, E. (2010). Validity and reliability of Turkish version of "Hospital Survey on Patient Safety Culture" and perception of patient safety in public hospitals in Turkey. BMC Health Services Research, 10(28). doi:10.1186/1472-6963-10-28

Bognar, A., Barach, P., Johnson, J. K., Duncan, R. C., Birnbach, D., Woods, D. , Bacha, E. A. (2008). Errors and the burden of errors: Attitudes, perceptions, and the culture of safety in pediatric cardiac surgical teams. The Annals of Thoracic Surgery, 85, 1374-1381. Center for Disease Control and Prevention. (2014). National vital statistics 2001, disease data. Retrieved February 20, 2014 from http://www.cdc.gov/nchs/products/nvsr.htm

Çelen, Ö., Teke, A., Cihangiroğlu, N. (2014). Investigating the patient safety culture level in Gülhane Military Medical Faculty Training Hospital. Gülhane Tıp Dergisi, 56, 85-92.

Dağdelen, Ü. A. (2014). Evaluation of patient safety culture in the learning organization (Master's thesis, Süleyman Demirel University, Institute of Social Sciences Department of Health Management, Isparta, Turkey). Retrieved from https://tez.yok.gov.tr/ UlusalTezMerkezi/ 
Fleming, M., \& Wentzell, N. (2008). Patient safety culture improvement tool: Development and guidelines for use. Healthcare Quarterly, 11(3), 10-15.

Gözlü, K. (2011). Evaluating the patient safety culture in a hospital with the certification of accreditation (Master's thesis, Hacettepe University, Institute of Health Sciences, Healthcare Management Program, Ankara, Turkey). Retrieved from https://tez.yok. gov.tr/UlusalTezMerkezi/

Gündoğdu, S., \& Bahçecik, N. (2012). Determining nurses' perception of patient safety culture. Anadolu Hemşirelik ve Sağlık Bilimleri Dergisi, 15(2), 119-128.

Harvard Medical Practice Study Group. (1990). Patients, doctors and lawyers: Medical injury, malpractice litigation and patient compensation in New York. Cambridge, Harvard University Press.

Koraşlı, D., Torun, E., Yüzden, G. E. (2010). Sağlık çalışanlarının hasta güvenliği kültürü algılamasının değerlendirilmesi: Eğitim ve Araştırma Hastanesi örneği. In II. Uluslararası Sağlıkta Performans ve Kalite Kongresi Bildiriler Kitabı (Vol. 1., pp. 442454). Antalya.

Kroeber, A. L., Kluckhohn, C., Untereiner, W., \& Meyer, A. G. (1952). Culture: A critical review of concepts and definitions. New York, NY: Vintage Books.

Mills, D. H. (1978). Medical insurance feasibility study-a technical summary. The Western Journal of Medicine, 128(4), 360-363.

Nieva, V. F., \& Sorra, J. (2003). Safety culture assessment: A tool for improving patient safety in healthcare organizations. Quality and Safety in Health Care, 12, 17-23.

Schimmel, E. M. (1964). The hazards of hospitalisation. Annals of Internal Medicine, $60,100-110$.

Small, S. D., \& Barracch, P. (2002). Patient safety and health policy: A history and review. Hematologic Oncology North America, 16(6), 1463-1482.

Sur, H., \& Palteki, T. (2013). Hastane yönetimi. İstanbul: Nobel T1p Kitabevleri.

Tanrıkulu, G. (2010). Hemşirelerin hasta ve hemşire güvenliği açısından acil servislerin çalışma ortamına iliş̧kin görüşleri (Master's thesis, Gazi University, Ankara, Turkey). Retrieved from https://tez.yok.gov.tr/UlusalTezMerkezi/.

Teleş, M. (2011). Analysis of the relation between the perception of health personnel on patients' safety culture and the perception of patients on the quality of the health service (Master's thesis, Hacettepe University, Health Sciences Institute of Health Institutions Management Program, Ankara, Turkey). Retrieved from https://tez.yok.gov.tr/UlusalTezMerkezi/ 
Türk Dil Kurumu. (2005). Güvenlik. In Türkçe sözlük (10. ed., p. 817). Ankara: 4. Akşam Sanat Okulu Matbaası.

Yang, C. C., Wang, Y. S., Chang, S. T., Guo, S. E., \& Huang, M. F. (2009). A study on the leadership behavior, safety culture, and safety performance of the healthcare industry. World Academy of Science, Engineering and Technology, 53 1148-1155.

Yardımcı, F., Başbakkal, Z., Beytut, D., Muslu, G., Ersun, A. (2014). Investigation of patient safety culture perception of health professionals in a state hospital. The Anatolian Journal of Clinical Investigation, 8(4), 173-179.

Zhang, D. A., Wiegmann, H., Von Thaden, T. L., Sharma, G., Gibbons, A. M. (2004). Safety culture: An integrative review. International Journal of Aviation Psychology, 14(2), 117-134. 